\title{
Ductal carcinoma in situ and sentinel lymph node metastasis in breast cancer
}

\author{
Keiichiro Tada ${ }^{{ }^{*}}$, Akiko Ogiya ${ }^{2}$, Kiyomi Kimura' ${ }^{1}$, Hidetomo Morizono ${ }^{1}$, Kotaro lijima', Yumi Miyagi ${ }^{1}$, \\ Seiichiro Nishimura', Masujiro Makita', Rie Horii', Futoshi Akiyama², Takuji Iwase'
}

\begin{abstract}
Background: The impact of sentinel lymph node biopsy on breast cancer mimicking ductal carcinoma in situ (DCIS) is a matter of debate.

Methods: We studied the rate of occurrence of sentinel lymph node metastasis in 255 breast cancer patients with pure DCIS showing no invasive components on routine pathological examination. We compared this to the rate of occurrence in 177 patients with predominant intraductal-component (IDC) breast cancers containing invasive foci equal to or less than $0.5 \mathrm{~cm}$ in size.
\end{abstract}

Results: Most of the clinical and pathological baseline characteristics were the same between the two groups. However, peritumoral lymphatic permeation occurred less often in the pure DCIS group than in the IDCpredominant invasive-lesion group (1.2\% vs. $6.8 \%, p=0.002)$. One patient $(0.39 \%)$ with pure DCIS had two sentinel lymph nodes positive for metastasis. This rate was significantly lower than that in patients with IDC-predominant invasive lesions (6.2\%; $p<0.001)$.

Conclusions: Because the rate of sentinel lymph node metastasis in pure DCIS is very low, sentinel lymph node biopsy can safely be omitted.

\section{Introduction}

The technique of sentinel lymph node biopsy is used worldwide as a surgical treatment for breast cancer $[1,2]$. This procedure can accurately determine lymph node metastasis [3,4]. Therefore morbid axillary dissection can be safely avoided when sentinel lymph nodes are free from cancer $[5,6]$.

The primary indication for sentinel lymph node biopsy is invasive breast cancer, which has the potential of metastasizing to the regional lymph nodes. On the other hand, ductal carcinoma in situ (DCIS), which has no invasive foci and is isolated from the interstitium, is not believed to metastasize to the lymph nodes [7].

The determination of DCIS requires thorough examination of surgical materials, and very infrequent lymph node metastases are observed in cases of DCIS that show no invasive components on routine pathological examination [8]. Furthermore, thorough examination of the sentinel lymph nodes, which are the most likely

\footnotetext{
* Correspondence: ktada@jfcr.or.jp

'Department of Breast Surgery, Cancer Institute Hospital, Tokyo, Japan
}

candidates for metastasis, is feasible. In these situations, some investigators have argued that more than a few cases of pure DCIS are accompanied by sentinel lymph node metastasis, and the indications for sentinel lymph node biopsy should be extended not only to cases with invasive cancer, but also to those with pure DCIS [9]. However, others have argued that the incidence of lymph node metastasis in pure DCIS is still very low, and sentinel lymph node biopsy can be safely avoided in these cases $[10,11]$.

In this article, we studied the incidence of sentinel lymph node metastasis in cases of pure DCIS. Furthermore, we compared this incidence with that of predominant intraductal-component (IDC) breast cancer with invasive foci equal to or less than $0.5 \mathrm{~cm}$ in size. Then we addressed the question of whether sentinel lymph node biopsy is required in cases of pure DCIS.

\section{Materials and methods \\ Patients and study design}

We searched our surgical records from December 2006 to June 2008 for patients with a histology of pure DCIS 
for our study. Pure DCIS was determined histopathologically as intraductal carcinoma without stromal invasion. Inclusion criteria were as follows: curative surgical treatment, performance of sentinel lymph node biopsy, and no primary chemotherapy. Patients with metachronous ipsilateral breast cancer were excluded. Furthermore, we also searched for patients having an IDC-predominant invasive lesion with the same profile as mentioned above. IDC-predominant invasive lesions are those with a predominant IDC including one or more invasive foci, each of which is not more than $0.5 \mathrm{~cm}$ in size.

\section{Sentinel lymph node biopsy procedures}

The method for sentinel lymph node biopsy using a radioactive agent has been described elsewhere [12]. Briefly, the radioactive tracer used was $1.5 \mathrm{mCi} / \mathrm{ml}$ of $99 \mathrm{mTc}$-phytate (Daiichi Radioisotope Laboratories, Ltd). The radioactive tracer was injected into the intradermal space in the area of the tumor and the retro-tumoral space. The tracer was injected the day prior to surgery. In all cases, a lymphoscintigraphy was obtained one hour after injection. Additionally, vital dye (indigocarmine) was injected intradermally in the peri-tumoral space just before surgery.

\section{Histopathological procedures}

Surgical materials from breast-conserving surgery were sectioned at $0.5 \mathrm{~cm}$ intervals, and each section was examined histologically. Surgical materials from mastectomy were cut at several representative sections in order to study the histopathological characteristics.

Sentinel lymph nodes were sectioned at $0.2 \mathrm{~cm}$ intervals, and examinations were based on frozen sections in most cases. Whether or not metastasis was present was determined intraoperatively. Immunohistochemistry was not used for analysis.

\section{Statistical analysis}

Frequency analysis was performed with Fisher's exact test. The difference in continuous variables was evaluated using Student's t-test. A significance level of 0.05 was used for statistical tests, and two-tailed tests were applied. Calculations were performed using SPSS 16.0J for MAC (SPSS Japan Inc. Tokyo).

\section{Results}

\section{Study population}

From December 2006 to June 2008, 1919 surgical and pathological records were registered. Among these, 1302 cases had sentinel lymph node biopsy and no primary chemotherapy. In this cohort, 255 patients had pure DCIS and 177 patients had an IDC-predominant invasive lesion. During the same period, there were 42 cases who had pure DCIS without sentinel lymph node biopsy.

\section{Patient characteristics}

The patients' characteristics are summarized in Table 1.

Most clinical and pathological baseline characteristics showed no differences between the groups, including age, estrogen receptor status, progesterone receptor status, removed sentinel nodes, and surgical procedures. However, the frequency of peritumoral lymphatic invasion was higher in the IDC-predominant invasive-lesion group than in the pure DCIS group (6.8\% vs $1.2 \%$ : $\mathrm{p}=$ 0.002).

\section{Patients with a positive sentinel node biopsy}

One patient $(0.39 \%)$ with pure DCIS had two sentinel lymph nodes positive for metastasis, whereas $6.2 \%$ of the patients with IDC-predominant invasive breast cancer had positive sentinel lymph nodes. Therefore, the risk of lymph node metastasis was significantly lower in the pure DCIS group than in the IDC-predominant invasive-lesion group, with a statistical significance of $\mathrm{p}<$ 0.001 . The contingency table for the two groups is shown in Table 2.

The major characteristics of node-positive patients with pure DCIS or IDC-predominant invasive lesions

Table 1 Patient characteristics

\begin{tabular}{|c|c|c|c|c|}
\hline & & Pure DCIS & $\begin{array}{c}\text { IDC predominant } \\
\text { invasive lesion }\end{array}$ & P-value \\
\hline Mean Age & (Range) & $51.2(29-81)$ & $51.9(27-86)$ & ${ }^{*} \mathrm{NS}$ \\
\hline \multicolumn{2}{|c|}{ Lymphatic permeation } & $3(1.2 \%)$ & $12(6.8 \%)$ & 0.002 \\
\hline \multicolumn{2}{|c|}{ Breast-conserving surgery } & $147(57.6 \%)$ & $96(54.2 \%)$ & NS \\
\hline \multirow[t]{3}{*}{$\overline{E R}$} & positive & $194(74.9 \%)$ & $133(76.8 \%)$ & NS \\
\hline & negative & $49(19.2 \%)$ & $36(20.3 \%)$ & \\
\hline & unknown & 15(5.9\%) & $5(2.8 \%)$ & \\
\hline \multirow[t]{3}{*}{$\overline{P g R}$} & positive & $162(62.8 \%)$ & $114(65.5 \%)$ & NS \\
\hline & negative & $81(31.4 \%)$ & $55(31.6 \%)$ & \\
\hline & unknown & $15(5.8 \%)$ & $5(2.8 \%)$ & \\
\hline
\end{tabular}

\footnotetext{
* NS; Not Specific
} 
Table 2 Contingency table

\begin{tabular}{cccc}
\hline & Node-positive & Node-negative & Total \\
\hline Pure DCIS & 1 & 254 & 255 \\
IDC predominant invasive lesion & 11 & 166 & 177 \\
\hline $\mathrm{p}<0.001$ & 12 & 420 & 432 \\
\hline
\end{tabular}

are summarized in Table 3 . The patient with pure DCIS had exclusive breast-conserving surgery, with a slight positive surgical margin, and received radiation therapy. Among the 11 patients who had an IDC-predominant invasive lesion with positive sentinel nodes, 4 patients had dislocation of cancer cells along the biopsy scar.

\section{Discussion}

In this study, we found that the incidence of sentinel lymph node metastasis in cases of pure DCIS was $0.39 \%$. This incidence was significantly lower than that in cases of IDC-predominant invasive tumors ( $0.39 \%$ vs. $6.2 \%$; $\mathrm{p}<$ 0.001 ). Therefore, our data suggest that sentinel lymph node biopsy can be avoided in cases of pure DCIS.

Many publications concerning this issue have reported only the rate of sentinel lymph node metastasis in pure DCIS. We also calculated the rate of metastasis in IDCpredominant invasive lesions. We believe that the relevance of the metastasis rate in pure DCIS is supported by comparing data concerning IDC-predominant invasive lesions. Furthermore, we can estimate the rate of sentinel lymph node metastasis in lesions mimicking DCIS clinically.

The issue of pure DCIS and sentinel node biopsy is associated with two major problems: one is that preoperative diagnosis of pure DCIS is difficult, and the other is that postoperative definitive diagnosis of pure DCIS is also difficult.

It is well known that preoperative diagnoses of DCIS based on core needle biopsy are likely to be underestimated. Rates of diagnosis range from $8.3 \%$ to $43.6 \%$ $[8,13,14]$. Preoperative core needle biopsy does not guarantee that the entire lesion is without stromal invasion. Furthermore, having less than $0.5 \mathrm{~cm}$ of stromal invasion increases the incidence of sentinel lymph node metastases $[15,16]$. As a result, many investigators insist that sentinel lymph node biopsy should be encouraged when DCIS-like tumors are large enough to be palpable or when tumors require total mastectomy.

Table 3 Patients with positive nodes

\begin{tabular}{|c|c|c|c|c|c|c|c|c|}
\hline & Age & $\begin{array}{l}\text { Clinical } \\
\text { presentation }\end{array}$ & Histology & Comedonecrosis & $\begin{array}{l}\text { Number of } \\
\text { positive nodes }\end{array}$ & $\begin{array}{l}\text { Size of metastasis } \\
\text { in nodes }\end{array}$ & $\begin{array}{l}\text { Lymphatic } \\
\text { permeation }\end{array}$ & $\begin{array}{l}\text { Tumor } \\
\text { dislocation }\end{array}$ \\
\hline 1 & 46 & $\begin{array}{l}\text { US-detected } \\
\text { mass }\end{array}$ & Pure DCIS & no & 2 & macro & None & none \\
\hline 2 & 48 & Palpable mass & $\begin{array}{l}\text { IDC predominant } \\
\text { invasive lesion }\end{array}$ & no & 1 & micro & Present & yes \\
\hline 3 & 29 & Palpable mass & $\begin{array}{l}\text { IDC predominant } \\
\text { invasive lesion }\end{array}$ & yes & 1 & micro & Present & yes \\
\hline 4 & 48 & $\begin{array}{l}\text { Nipple } \\
\text { discharge }\end{array}$ & $\begin{array}{l}\text { IDC predominant } \\
\text { invasive lesion }\end{array}$ & no & 1 & micro & None & yes \\
\hline 5 & 54 & $\begin{array}{l}\text { Calcification on } \\
\text { MMG }\end{array}$ & $\begin{array}{l}\text { IDC predominant } \\
\text { invasive lesion }\end{array}$ & no & 1 & ND & None & none \\
\hline 6 & 45 & Palpable mass & $\begin{array}{l}\text { IDC predominant } \\
\text { invasive lesion }\end{array}$ & yes & 2 & macro & None & none \\
\hline 7 & 45 & $\begin{array}{l}\text { Calcification on } \\
\text { MMG }\end{array}$ & $\begin{array}{l}\text { IDC predominant } \\
\text { invasive lesion }\end{array}$ & yes & 1 & micro & None & none \\
\hline 8 & 53 & Palpable mass & $\begin{array}{l}\text { IDC predominant } \\
\text { invasive lesion }\end{array}$ & no & 2 & micro & None & none \\
\hline 9 & 54 & $\begin{array}{l}\text { Nipple } \\
\text { discharge }\end{array}$ & $\begin{array}{l}\text { IDC predominant } \\
\text { invasive lesion }\end{array}$ & yes & 1 & macro & None & none \\
\hline 10 & 65 & Palpable mass & $\begin{array}{l}\text { IDC predominant } \\
\text { invasive lesion }\end{array}$ & yes & 1 & macro & None & none \\
\hline 11 & 50 & Palpable mass & $\begin{array}{l}\text { IDC predominant } \\
\text { invasive lesion }\end{array}$ & yes & 1 & macro & None & none \\
\hline 12 & 44 & Palpable mass & $\begin{array}{l}\text { IDC predominant } \\
\text { invasive lesion }\end{array}$ & no & 1 & micro & None & yes \\
\hline
\end{tabular}

Abbreviations: US; Ultrasonography, MMG; Mammography, ND; Not Determined 
Furthermore, the postoperative pathological diagnosis of pure DCIS does not always guarantee the absence of lymph node metastasis. For many years, it has been believed that DCIS is associated with the absence of lymph node metastasis, that axillary dissection in DCIS could be omitted, and that cases of lymph node metastasis in DCIS are associated with invasive lesions that are too small to be detected by the usual pathological examination. However, in regular clinical practice the detection of minimal stromal invasion is quite difficult. Although sentinel lymph node biopsy is effective in DCIS, we suggest that the application of sentinel node biopsy to all DCIS cases should be avoided. That is because, although sentinel node biopsy is less morbid than axillary dissection, the procedure is not completely free from morbidity [17].

We believe that Moore et al., who encouraged the use of sentinel lymph node biopsy in pure DCIS, does not argue that sentinel lymph node biopsy should be carried out in all cases of pure DCIS [9]. In their literature, only $22 \%$ of all DCIS cases had sentinel lymph node biopsy. The relatively high rate of axillary lymph node metastases in their study can be associated with this selection.

In our series there was one case of pure DCIS with positive sentinel nodes. This case underwent a partial mastectomy, and the surgical margin was slightly positive. Preoperative mammography, ultrasonography, and MRI did not reveal any other abnormal lesions besides the main tumor. However two sentinel nodes were positive for cancer and both metastases were larger than 2 $\mathrm{mm}$. We think that this was an extremely rare case. Although some authors encourage the preservation of axillary nodes in cases of pure DCIS with positive sentinel nodes [10], an axillary dissection was performed in this patient.

There is much debate concerning the association between preoperative invasive procedures for diagnosis and the likelihood of lymph node metastases. Displacement of cancer cells around the main tumor is common, and frequencies from $28 \%$ to $32 \%$ have been reported previously $[18,19]$. Moreover, there is the possibility that displacement can cause the migration of cancer cells to lymph nodes[20]. However, the prognostic significance of this migration is uncertain. Previous studies show that large gauge needle biopsy does not affect the survival risk $[21,22]$. Much more discussion and careful studies on this issue are necessary.

Our study has a considerable limitation. Our series could miss cases of micrometastases or isolated tumor cells (ICT) in sentinel nodes. In order to avoid this problem, the sentinel nodes should be sectioned at intervals of at least $0.15 \mathrm{~mm}$ and immunohistochemistry should be applied to sections at different levels. These analyses should be performed on permanent paraffin sections.
Although the clinical significance of micrometastases and ICT in DCIS has been unclear [23], the latest report has shown that micrometastases or ICT may decrease the probability of survival in invasive breast cancers [24].

In conclusion, we found that the incidence of sentinel lymph node metastasis in cases of pure DCIS was $0.39 \%$. This incidence was lower than that in IDC-predominant invasive lesions. Therefore, we believe that sentinel lymph node biopsy in pure DCIS can be safely omitted.

\section{Acknowledgements}

This work was supported in part by a Grant-in-Aid for Cancer Research (2016) from the Ministry of Health, Labour and Welfare.

\section{Author details}

'Department of Breast Surgery, Cancer Institute Hospital, Tokyo, Japan.

${ }^{2}$ Department of Pathology, The Cancer Institute of the Japanese Foundation for Cancer Research, Tokyo, Japan.

\section{Authors' contributions}

$\mathrm{KT}$ designed the study, researched the literature, and drafted the manuscript. $\mathrm{FA}, \mathrm{RH}$, and $\mathrm{AO}$ contributed to the histopathological analyses. KK, HM, KI, YM, SN, MM, and TI participated in the study design and coordination, and helped to collect data.

\section{Competing interests}

The authors declare that they have no competing interests.

\section{Received: 19 August 2009}

Accepted: 27 January 2010 Published: 27 January 2010

\section{References}

1. Krag D, Weaver D, Ashikaga T, Moffat F, Klimberg VS, Shriver C, Feldman S, Kusminsky R, Gadd M, Kuhn J, Harlow S, Beitsch P: The sentinel node in breast cancer-a multicenter validation study. N Engl J Med 1998, 339:941-946.

2. Veronesi U, Paganelli G, Viale G, Luini A, Zurrida S, Galimberti V, Intra M, Veronesi P, Robertson C, Maisonneuve P, Renne G, De Cicco C, De Lucia F, Gennari R: A randomized comparison of sentinel-node biopsy with routine axillary dissection in breast cancer. N Engl J Med 2003, 349:546-553.

3. Kim T, Giuliano AE, Lyman GH: Lymphatic mapping and sentinel lymph node biopsy in early-stage breast carcinoma: a metaanalysis. Cancer 2006, 106:4-16.

4. Barone JE, Tucker JB, Perez JM, Odom SR, Ghevariya V: Evidence-based medicine applied to sentinel lymph node biopsy in patients with breast cancer. Am Surg 2005, 71:66-70.

5. Lucci A, McCall LM, Beitsch PD, Whitworth PW, Reintgen DS, Blumencranz PW, Leitch AM, Saha S, Hunt KK, Giuliano AE: Surgical complications associated with sentinel lymph node dissection (SLND) plus axillary lymph node dissection compared with SLND alone in the American College of Surgeons Oncology Group Trial Z0011. J Clin Oncol 2007, 25:3657-3663.

6. Zavagno G, De Salvo GL, Scalco G, Bozza F, Barutta L, Del Bianco P, Renier M, Racano C, Carraro P, Nitti D: A Randomized clinical trial on sentinel lymph node biopsy versus axillary lymph node dissection in breast cancer: results of the Sentinella/GIVOM trial. Ann Surg 2008, 247:207-213.

7. Burstein HJ, Polyak K, Wong JS, Lester SC, Kaelin CM: Ductal carcinoma in situ of the breast. N Engl J Med 2004, 350:1430-1441.

8. Ansari B, Ogston SA, Purdie CA, Adamson DJ, Brown DC, Thompson AM: Meta-analysis of sentinel node biopsy in ductal carcinoma in situ of the breast. Br J Surg 2008, 95:547-554.

9. Moore KH, Sweeney KJ, Wilson ME, Goldberg Jl, Buchanan CL, Tan LK, Liberman L, Turner RR, Lagios MD, Cody lii HS, Giuliano AE, Silverstein MJ, Van Zee KJ: Outcomes for women with ductal carcinoma-in-situ and a 
positive sentinel node: a multi-institutional audit. Ann Surg Oncol 2007, 14:2911-2917.

10. Intra M, Rotmensz N, Veronesi P, Colleoni M, lodice S, Paganelli G, Viale G, Veronesi $U$ : Sentinel node biopsy is not a standard procedure in ductal carcinoma in situ of the breast: the experience of the European institute of oncology on 854 patients in 10 years. Ann Surg 2008, 247:315-319.

11. Zavagno G, Carcoforo P, Marconato R, Franchini Z, Scalco G, Burelli P, Pietrarota P, Lise M, Mencarelli R, Capitanio G, Ballarin A, Pierobon ME, Marconato G, Nitti D: Role of axillary sentinel lymph node biopsy in patients with pure ductal carcinoma in situ of the breast. BMC Cancer 2005, 5:28.

12. Tada K, Nishimura S, Miyagi Y, Takahashi K, Makita M, Iwase T, Yoshimoto M, Kasumi F, Koizumi M: The effect of an old surgical scar on sentinel node mapping in patients with breast cancer: a report of five cases. Eur I Surg Oncol 2005, 31:840-844.

13. Londero V, Zuiani C, Furlan A, Nori J, Bazzocchi M: Role of ultrasound and sonographically guided core biopsy in the diagnostic evaluation of ductal carcinoma in situ (DCIS) of the breast. Radiol Med 2007, 112:863-876

14. Polom K, Murawa D, Wasiewicz J, Nowakowski W, Murawa P: The role of sentinel node biopsy in ductal carcinoma in situ of the breast. Eur J Surg Oncol 2009, 35:43-47.

15. Fortunato L, Santoni M, Drago S, Gucciardo G, Farina M, Cesarini C, Cabassi A, Tirelli C, Terribile D, Grassi GB, De Fazio S, Vitelli CE, Rome Breast Cancer Study Group: Sentinel lymph node biopsy in women with pT1a or "microinvasive" breast cancer. Breast 2008, 17:395-400.

16. Zavagno G, Belardinelli V, Marconato R, Carcoforo P, Franchini Z, Scalco G, Burelli P, Pietrarota P, Mencarelli R, Marconato G, Nitti D: Sentinel lymph node metastasis from mammary ductal carcinoma in situ with microinvasion. Breast 2007, 16:146-151.

17. Burak WE, Hollenbeck ST, Zervos EE, Hock KL, Kemp LC, Young DC: Sentinel lymph node biopsy results in less postoperative morbidity compared with axillary lymph node dissection for breast cancer. Am J Surg 2002, 183:23-27.

18. Youngson BJ, Liberman L, Rosen PP: Displacement of carcinomatous epithelium in surgical breast specimens following stereotaxic core biopsy. Am J Clin Pathol 1995, 103:598-602.

19. Diaz LK, Wiley EL, Venta LA: Are malignant cells displaced by large-gauge needle core biopsy of the breast?. AJR Am J Roentgenol 1999, 173:1303-1313.

20. Bleiweiss IJ, Nagi CS, Jaffer S: Axillary sentinel lymph nodes can be falsely positive due to iatrogenic displacement and transport of benign epithelial cells in patients with breast carcinoma. J Clin Oncol 2006, 24:2013-2018.

21. Fitzal F, Sporn EP, Draxler W, Mittlbock M, Taucher S, Rudas M, Riedl O, Helbich TH, Jakesz R, Gnant M: Preoperative core needle biopsy does not increase local recurrence rate in breast cancer patients. Breast Cancer Res Treat 2006, 97:9-15.

22. Peters-Engl C, Konstantiniuk P, Tausch C, Haid A, Hoffmann B, JagoutzHerzlinger M, Kugler F, Redtenbacher S, Roka S, Schrenk P, Steinmassl D: The impact of preoperative breast biopsy on the risk of sentinel lymph node metastases: analysis of 2502 cases from the Austrian Sentinel Node Biopsy Study Group. Br J Cancer 2004, 91:1782-1786.

23. Broekhuizen $\mathrm{LN}$, Wijsman $J H$, Peterse $J \mathrm{~L}$, Rutgers EJ: The incidence and significance of micrometastases in lymph nodes of patients with ductal carcinoma in situ and T1a carcinoma of the breast. Eur J Surg Oncol 2006, 32:502-506.

24. de Boer $M$, van Deurzen $C H$, van Dijck JA, Borm GF, van Diest PJ, Adang EM, Nortier JW, Rutgers EJ, Seynaeve C, Menke-Pluymers MB, Bult P, Tjan-Heijnen VC: Micrometastases or isolated tumor cells and the outcome of breast cancer. N Engl J Med 2009, 361:653-663.

doi:10.1186/1477-7819-8-6

Cite this article as: Tada et al:: Ductal carcinoma in situ and sentinel

lymph node metastasis in breast cancer. World Journal of Surgical Oncology 2010 8:6

\section{Submit your next manuscript to BioMed Central and take full advantage of:}

- Convenient online submission

- Thorough peer review

- No space constraints or color figure charges

- Immediate publication on acceptance

- Inclusion in PubMed, CAS, Scopus and Google Scholar

- Research which is freely available for redistribution

Submit your manuscript at www.biomedcentral.com/submit 